\title{
PROLAPSO DE GLÂNDULA DE TERCEIRA PÁLPEBRA EM CÃES: AVALIAÇÃO CITO E HISTOPATOLÓGICA
}

\section{(Prolapsed third eyelid gland in dogs: cytologic and histopathologic evaluation)}

\author{
BRANDÃO, C. V. S. ${ }^{1}$; ROCHA, N. S. ${ }^{2}$; RANZANI, J. J. T. ${ }^{1}$; ANTUNES, P. A. C. ${ }^{3}$; TORELLI, S. R \\ ${ }^{1}$ Departamento de Cirurgia e Anestesiologia Veterinária - FMVZ - Unesp - Botucatu - e-mail: valeriasb@ \\ fmvz.unesp.br \\ ${ }^{2}$ Departamento de Clínica Veterinária - Anatomopatologia Veterinária - FMVZ - Unesp - Botucatu \\ ${ }^{3}$ Pós-Graduando - Departamento de Cirurgia e Anestesiologia Veterinária - FMVZ - Unesp - Botucatu.
}

\begin{abstract}
RESUMO - No presente trabalho dez cães apresentando glândulas da terceira pálpebra prolapsadas foram submetidos à excisão cirúrgica e avaliação cito e histopatológica. A idade dos cães variou de dois meses a dez anos, sendo das raças Beagle (20\%), Teckel (10\%), Pinscher (10\%), Poodle (10\%) e SRD. As glândulas removidas foram aspiradas por agulha fina para o exame de citologia aspirativa e a seguir, fixadas em formalina a $10 \%$ e coradas por HE. Aos cortes histológicos foi possível observar infiltrado inflamatório predominantemente mononuclear focal na conjuntiva e região periacinar. Observou-se dilatação no lúmen dos ductos e metaplasia. No exame citológico, notou-se infiltrado inflamatório semelhante ao histopatológico. As glândulas apresentaram uma adenite crônica. A ausência de mudanças cito e histopatológicas notáveis demonstrou um tecido glandular funcional no momento da excisão cirúrgica.
\end{abstract}

Palavras-chave: glândula de terceira pálpebra; cão; histopatologia.

\begin{abstract}
The present experiment was carried out in ten animals with third eyelid prolapsed gland. All of the prolapsed glands were surgically excised. The age of the dogs ranged from two month to ten years old, and the breeds were Beagle $(20 \%)$, Teckel (10\%), Pinscher (10\%), Poodle $(10 \%)$ and other mongrel dogs. Aspirative citology was made in all the removed glands, after that they were fixed in 10\% formalin and stained with Hematoxiline and Eosine. It was observed a focal mononuclear inflamatory infiltrate in the conjunctive and periacinal tissues. Ductal dilatation and metaplasia were noted on cells of the ducts. Cyitologic examination showed similar inflamatory infiltrate to histopatologic findings. The glands showed a chronic adenitis. The absence of histo and cytologic significance changes justify the tissue function observed during surgical excision.
\end{abstract}

Key-words: third eyelid gland; dog; histopathology. 


\section{INTRODUÇÃO}

A produção lacrimal em cães é referida como sendo originada da glândula lacrimal principal $(70 \%)$ e da glândula da terceira pálpebra (30\%) (SAITO et al., 2001; GELATT, 2003). HELPER et al. (1974) referem que o volume da produção lacrimal diminui cerca de 10 a $37 \%$ (média de $23 \%$ ) com a remoção da glândula lacrimal e cerca de 29 a 57\% (média de $42 \%$ ) com a remoção da glândula de terceira pálpebra. O prolapso de glândula de terceira pálpebra, também conhecido como hipertrofia, "cherry eye", é uma afecção freqüentemente observada nos cães (DUGAN et al., 1992; MOORE, 1999; WARD, 1999). Tem-se sugerido que o tecido conjuntivo localizado entre a base da glândula e o tecido periorbital é pouco desenvolvido nos cães com prolapso e esta alteração pode ser de origem congênita ou ainda hereditária (HELPER, 1981; WARD, 1999; GELATT, 2003). Hiperplasia, neoplasia e inflamação primária não estão relacionadas à causa primária desta afecção. Os sintomas observados são a presença de massa avermelhada no canto medial do olho acometido, podendo haver conjuntivite e epífora (MOORE, 1999). Inflamação secundária e edema resultam da exposição da glândula (HELPER, 1981).

Os animais jovens são os mais comumente acometidos e dentre as raças predispostas podemos citar o Cocker Spaniel, Beagle, Bulldog inglês, Lhasa apso, Basset hound, Boston terrier e Shih tzu (BARNETT, 1978; DUGAN et al., 1992).

A excisão da glândula prolapsada é um dos tratamentos de escolha. No entanto, o controle da produção de lágrima deve ser feito por meio do teste de lágrima de Schirmer e a excisão pode ser considerada se a produção de lágrima estiver acima da variação normal (WARD, 1999). Por ser importante contribuinte na produção do filme lacrimal, a sua remoção pode acelerar o desenvolvimento de ceratoconjuntivite seca (KCS) que é caracterizada por uma diminuição da quantidade e/ou qualidade do filme lacrimal (ROLANDO e ZIERHUT, 2001; ALMEIDA et al., 2004; COASSIM et al., 2005), principalmente nas raças predispostas (HELPER, 1981; MOORE, 1999). A fixação da glândula em sua posição ou mesmo a manutenção desta, prolapsada, podem ser preferíveis à remoção (DUGAN et al., 1992); contudo, outros autores citam que a glândula prolapsada não tratada pode também ser causa de ceratoconjuntivite seca (BARNETT, 1978).

Terapia não específica com antibióticos e antiinflamatórios à base de esteróides não resulta na resolução do prolapso, contudo, estes fármacos devem ser utilizados no período pós-operatório por 5 a 7 dias (HELPER, 1981).

A tendência atual para tratamento do prolapso da glândula da terceira pálpebra é o reposicionamento cirúrgico, entretanto, há poucos estudos a respeito do estado funcional das glândulas. Segundo BARNETT (1978), a glândula prolapsada apresenta histologicamente hiperplasia e adenite discreta (READ et al. 1996). DUGAN et al. (1992) compararam histopatologicamente glândulas prolapsadas excisadas e reposicionadas cirurgicamente; mudanças inflamatórias discretas foram observadas nas glândulas excisadas e, as reposicionadas cirurgicamente, apresentaram regiões de fibrose parenquimatosa atribuídas à inserção do fio de sutura. Outro estudo realizado nas glândulas de terceira pálpebra sem prolapso de cães portadores de ceratoconjuntivite seca revelou uma adenite crônica com predominância de linfócitos, sugerindo causa imunológica para a afecção (MARTIN et al., 1988).

O sistema lacrimal é constituído por porções secretora e excretora, responsáveis respectivamente pela produção e drenagem do filme lacrimal e, histologicamente, as glândulas lacrimais são constituídas por unidades secretoras, ductos e tecido conjuntivo de sustentação (CABRAL et al., 2005).

O propósito deste trabalho foi a avaliação cito e histopatológica das glândulas de terceira pálpebra prolapsadas de cães naturalmente afetados, com o objetivo de contribuir para o melhor entendimento anatomopatológico desta afecção.

\section{MATERIAL E MÉTODOS}

Foram avaliadas 14 glândulas de terceira pálpebra prolapsadas de dez cães atendidos no serviço de Cirurgia de Pequenos Animais da Faculdade de Medicina Veterinária e Zootecnia - UNESP - Campus de Botucatu. A idade dos cães variou de dois meses a dez anos, sendo das raças Beagle (20\%), Teckel $(10 \%)$, Pinscher $(10 \%)$, Poodle $(10 \%)$ e os demais $(50 \%)$ sem raça definida (SRD). Todos os cães foram submetidos a exame físico e oftálmico, incluindo-se o teste de lágrima de Schirmer, buscando-se outras possiveis alterações.

A excisão cirúrgica das glândulas prolapsadas foi feita em todos os animais. A cirurgia foi realizada sob anestesia geral inalatória com Halotano ${ }^{1}$. A anti-sepsia das pálpebras e do saco conjuntival foi feita com iodo povidine a $5 \%$. A excisão cirúrgica das glândulas foi realizada por meio do pinçamento da glândula prolapsada na sua base e incisão com

1 Halothano - Cristália - Produtos Químicos Farmacêuticos Ltda. 
auxílio de bisturi. No pós-operatório imediato foram utilizadas pomadas antibióticas à base de cloranfenicol'.

Todas as glândulas removidas foram submetidas ao exame de citologia aspirativa utilizando agulha fina (CAAF), em seguida foram fixadas em formalina a $10 \%$. O material foi processado histologicamente, incluído em parafina, cortado e corado pelos métodos de Hematoxilina e Eosina (HxE) para exame histopatológico, Giemsa para o exame citológico e examinados por meio de microscopia óptica.

\section{RESULTADOS E DISCUSSÂO}

No exame físico, não foram observadas alterações clínicas dignas de nota. No exame oftálmico, além do prolapso da glândula de terceira pálpebra (FIGURA 1), três animais apresentaram produção de lágrima inferior a $10 \mathrm{~mm} / \mathrm{min}$ pelo teste de lágrima de Schirmer. Apesar do valor de Schirmer referido, houve solicitação por parte dos proprietários para a ressecção cirúrgica das glândulas.

\section{FIGURA 1 - GLÂNDULA DA TERCEIRA PÁLPE- BRA PROLAPSADA COM FOLÍCU- LOS LINFÓIDES NA SUA SUPERFÍCIE EM CÃES.}

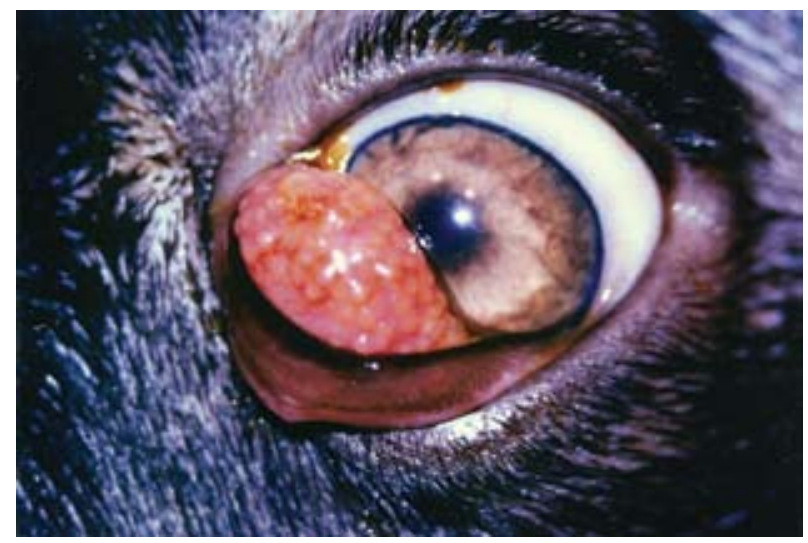

Aos cortes histológicos, foi possível observar infiltrado inflamatório predominantemente mononuclear focal (linfócitos e macrófagos) na conjuntiva e região periacinar (FIGURA 2). Além disso, observou-se dilatação no lume dos ductos bem como, metaplasia das células que os compõem (FIGURA 3).

\section{FIGURA 2 -CORTE HISTOPATOLÓGICO DA GLÂNDULA DA TERCEIRA PÁLPE- BRA PROLAPSADA DEMONSTRANDO INTENSO INFIL- TRADO INFLAMATÓRIO E DILATA- ÇÃO GLÂNDULAR EM CÃES (HE 200X).}

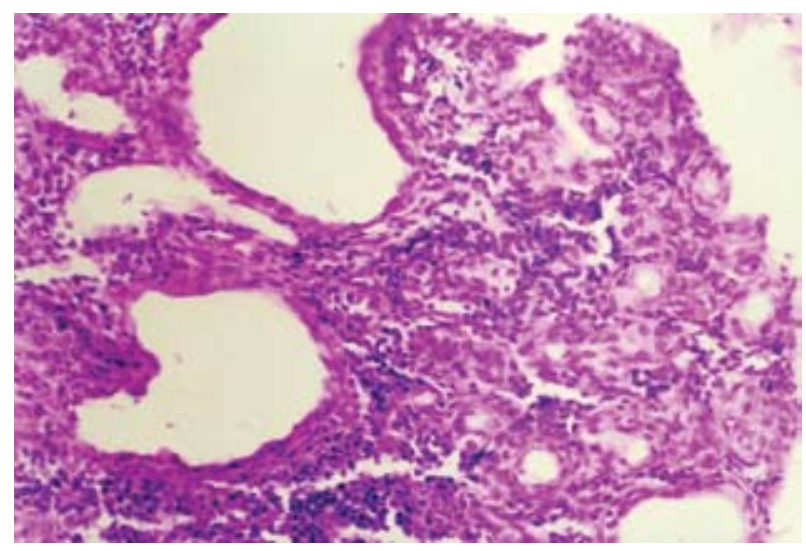

\section{FIGURA 3 - CORTE HISTOPATOLÓGICO DA GLÂNDULA DA TERCEIRA PÁLPE- BRA PROLAPSADA, EM CÃES. OBSERVAR A DILATA- ÇÃO GLÂNDULAR (HE 200X).}

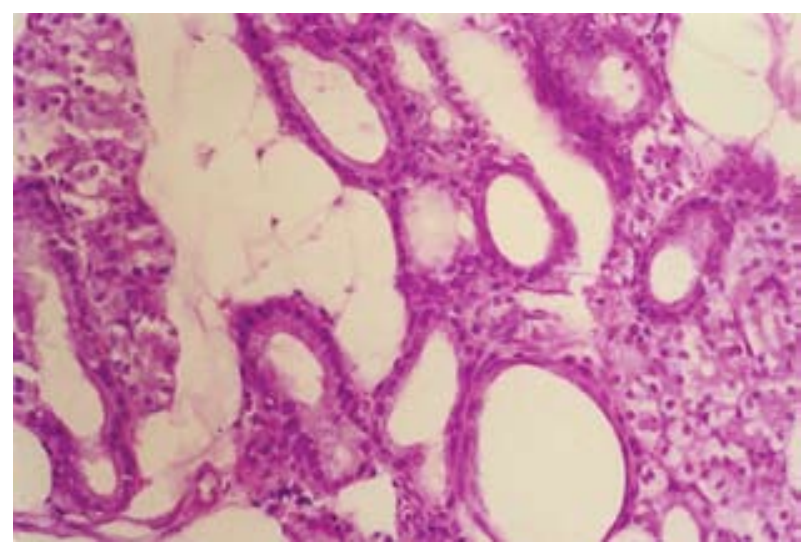

A terceira pálpebra apresenta tecido glândular tubuloacinar com grupos de células secretoras que 
se arranjam de forma lobular (MARTIN et al., 1988; DUGAN et al., 1992) No material estudado, estes lóbulos apresentaram-se dilatados e com ausência de secreção. Não foi observado o componente intersticial característico como lipócitos, mastócitos, plasmócitos e raros fibroblastos (SLATTER, 2005). Por outro lado, observou-se no exame histológico, tanto no interstício quanto no interior das glândulas, intenso tecido conjuntivo e células polimorfonucleares.

$\mathrm{Na}$ citologia (CAAF), foi visto infiltrado inflamatório semelhante ao encontrado no histopatológico. As células glandulares exibiam citoplasma vacuolizado e núcleo hipercromático. As glândulas apresentaram sinais de adenite crônica (FIGURA 4).

\section{FIGURA 4 - CITOLOGIAASPIRATIVA DA GLÂNDULA DE TERCEIRA PÁLPEBRA PROLAP- SADAEM CÃES. OBSERVARAS CÉLULAS GIGANTES ALTAMENTE REATIVAS DEVIDO AO INFILTRADO INFLAMATÓRIO (NEUTRÓFILOS, MONÓCITOS E EOSI- NÓFILOS) (GIEMSA 400X).}

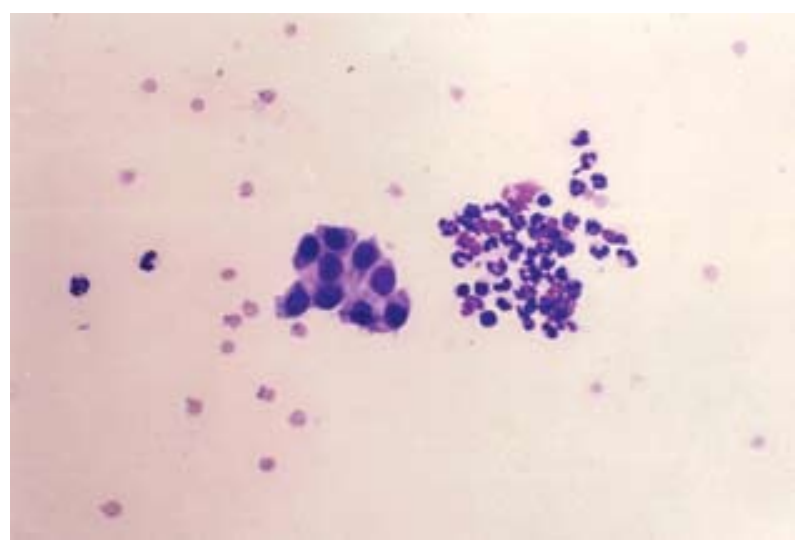

No exame citológico, somente o tecido intersticial não pode ser visto, contudo, os demais componentes puderam ser detectados, principalmente as células glandulares com infiltrado inflamatório. Alterações inflamatórias discretas inespecíficas foram identificadas nas glândulas excisadas, de acordo com a literatura (DUGAN et al., 1992), portanto, denotando a ausência de alterações histopatológicas notáveis, o que foi também observado no exame citológico.

DUGAN et al. (1992) relataram que a glândula reposicionada mostrou-se funcional, apesar de um decréscimo da produção de lágrima pelo teste de Schirmer quando comparada ao olho contralateral. No entanto, o decréscimo na produção glandular foi menor do que o resultado obtido nos casos de excisão (DUGAN et al., 1992).

\section{CONCLUSÕES}

A ausência de mudanças histopatológicas e citológicas notáveis demonstra tecido glandular funcional no momento da excisão cirúrgica.

$\mathrm{Na}$ histopatologia das glândulas prolapsadas, adenite suave é a alteração predominante.

O uso do exame citológico mostra-se eficiente na observação das alterações microscópicas da glândula de terceira pálpebra prolapsada.

O exame citológico, associado ao clínico, pode ser realizado para descartar a excisão da glândula apresentando apenas reação inflamatória.

\section{REFERÊNCIAS}

ALMEIDA, D. E.; MAMEDE, F. V.; ORTIZ, J. P. D.; LAUS, J. L. latrogenic Keratoconjuntivitis sicca in a dog. Ciência Rural, v. 34, n. 3, p. 921-924, 2004.

BARNETT, K. C., Diseases of the nictitating membrane of the dog. Journal of small animal practice, v. 19, p. 101-108, 1978.

CABRAL, V. P.; LAUS, J. L.; DAGLI, M. L. Z.; PEREIRA, G. T.; TALIERI, I. C.; MONTEIRO, E. R.; MAMEDE, F. V. Canine lacrimal and third eyelid superficial gland's macroscopic and morphometric characteristics. Ciência Rural. v. 35, n. 2, p. 391-397, 2005.

COASSIM, M.; LAMBIASE, A.; COSTA, N.; GREGORIO, A.; SGRULLETTA, R.; SACHETTI, M.; ALOE, L.; BONINI, S. Efficacy of topical nerve growth factor treatment in dogs affected by dry eye. Graefes' Archives of Clinical and Experimental Ophthalmology, v. 243, p. 151-155, 2005.

DUGAN, S. J.; SEVERIN, G. A.; HUNGERFORD, L. L.; WHITELEY, H. E.; ROBERTS, S. M. Clinical and histological evaluation of the prolapsed third eyelid gland in dogs. Journal of American Veterinary Medical Association, v. 201, p. 1861-1866,1992.

GELATT, K. N. Doenças e Cirurgia dos sistemas lacrimal e nasolacrimal do cão In: Manual de oftalmologia veterinária. Manole, São Paulo, 73-94, 2003.

HELPER, L. C.; MAGRANE, W. G.; KOEHM, J., Surgical induction of keratoconjuntivitis sicca in the 
dog. Journal of American Veterinary Medical Association, v. 165, p. 172-174, 1974.

HELPER, L. C. The canine nictitating membrane and conjunctiva. In: GELATT, K. N., Veterinary ophthalmology. Philadelphia: Lea e Febiger, 1981, p. $330-342$.

MARTIN, C. L..; MUNNELL, J.; KASWAN, R. Normal ultrastructure and histochemical characteristics of canine lacrimal glands. American Journal Veterinary Research, 1988, v. 49, p. 1566-1572.

MOORE, C. P. Diseases and surgery of the lacrimal secretory system. In: GELATT, K. N., Veterinary ophthalmology. $3^{\text {rd }}$ ed. Philadelphia: Williams $e$ Wilkins, 1999, p. 583-607.

READ, R. A, DUNN, K. A., SMITH, K. C., BARNETT, K. C. A histological study of nictitans glands from dogs with tear overflow of unknown cause. Veterinary Comparative Ophthalmology, v. 6, n. 3, p. 195-204,1996.

ROLANDO, M.; ZIERHUT M., The ocular surface and tear film and their disfunction in dry eye disease. Survey of Ophthalmology. v. 45, p. 203-210, 2001.

SAITO, A.; IZUMISAWA, Y.; YAMASHITA, K.; KOTANI, $T$. The effect of third eyelid gland removal on the ocular surface of dogs. Veterinary Ophthalmology, $4^{\text {th }}$ ed. 2001 , p. $13-18$.

SLATTER, D. Third eyelid. In: Fundamentos de Oftalmologia Veterinária. 3 ed. Rio de Janeiro: Roca, 2005, p. 226-236.

WARD, D. A. Diseases and surgery of the canine nictitating membrane. In: GELATT, K. N., Veterinary ophthalmology. 3 ed. Philadelphia: Williams $e$ Wilkins, 1999, p. 609.

Recebido para publicação:

$07 / 02 / 2007$

Aprovado:

$05 / 12 / 2007$ 